\title{
Proximal esophageal cancer missed during esopha- gogastroduodenoscopy: should the detection of an inlet patch be added to the quality criteria for upper gastrointestinal endoscopy?
}

\begin{abstract}
A 75-year-old woman was investigated by the pulmonologist for pulmonary abnormalities and weight loss. In the past she had undergone repeated endoscopic rubber-band ligations for bleeding esophageal varices. A combined positron emission tomography-computed tomography (PET-CT) scan revealed intense fluorodeoxyglucose (FDG) avidity in the proximal esophagus. An esophagogastroduodenoscopy (EGD) showed a squamous cell carcinoma just distal to the upper esophageal sphincter. Remarkably, an EGD 2 months earlier had been reported to be without abnormalities.
\end{abstract}

The proximal esophagus needs careful screening to detect esophageal carcinoma, especially in high risk patients [1]. A quality indicator for EGD could consist of the detection of an esophageal gastric inlet patch (GIP), which is present in $0.4 \%-11 \%$ of patients [2-4]. A required minimum lower limit for GIP detection rate (GIPDR) could result in a lower miss-rate for proximal abnormalities, in a manner similar to that for adenoma detection rate during colonoscopy [5].

In a retrospective cohort, we reviewed EGD reports for the presence of a GIP in both the text and images of the reports. Thereafter, consecutive patients undergoing an EGD were actively screened for the presence of a GIP. Diagnostic EGDs, performed mainly because of gastroesophageal reflux disease, dyspepsia, or anemia, were included in both groups. Exclusion criteria were therapeutic EGD or altered anatomy from mouth to duodenum.

The total population consisted of 157 patients: 65 men $(41 \%)$ and 92 women (59\%). Retrospective review of 95 EGD reports revealed no reported GIPs ( $0 \%$; $95 \%$ confidence interval [CI] $0.0 \%-3.8 \%$; in the prospective group, three GIPs were observed among the 62 patients $(4.8 \%$; $95 \%$ CI $1.0 \%-13.5 \% ; P=0.065)$.

Our case report and subsequent analysis of our GIPDR underline the importance of actively focusing on the proximal esophagus during EGD. GIPDR seems to be influenced by the awareness of the endoscopist. A lower limit of GIPDR could be helpful in improving the quality of EGD.

Endoscopy_UCTN_Code_CPL_1AH_2AK

Competing interests: None

Emma Paulides ${ }^{1}$, Nanne K. H. de Boer ${ }^{1}$, Matthijs E. Grasman ${ }^{1,2}$

${ }^{1}$ Department of Gastroenterology and Hepatology, VU University Medical Center, Amsterdam, The Netherlands

2 Department of Gastroenterology and Hepatology, Noordwest Ziekenhuisgroep, Alkmaar-Den Helder-Schagen, The Netherlands

\section{References}

1 Prabhu A, Obi KO, Rubenstein JH. The synergistic effects of alcohol and tobacco consumption on the risk of esophageal squamous cell carcinoma: a meta-analysis. Am J Gastroenterol 2014; 109: 822 - 827

2 Weickert $U$, Wolf A, Schroder C et al. Frequency, histopathological findings, and clinical significance of cervical heterotopic gastric mucosa (gastric inlet patch): a prospective study in 300 patients. Dis Esophagus 2011; 24: $63-68$

3 Park WG, Shaheen NJ, Cohen J et al. Quality indicators for EGD. Am J Gastroenterol 2015; 110: $60-71$

4 Azar C, Jamali F, Tamim H et al. Prevalence of endoscopically identified heterotopic gastric mucosa in the proximal esophagus: endoscopist dependent? J Clin Gastroenterol 2007; 41: 468-471

5 Rex DK, Schoenfeld PS, Cohen J et al. Quality indicators for colonoscopy. Gastrointest Endosc 2015; 81: 31-53

Bibliography

Dol http://dx.doi.org/

10.1055/s-0042-112980

Endoscopy 2016; 48: E273

(c) Georg Thieme Verlag KG

Stuttgart · New York

ISSN 0013-726X

\section{Corresponding author}

Matthijs E. Grasman, MD

Department of Gastroenterology and Hepatology VU University Medical Center

PO Box 7057, 1007 MB

Amsterdam

The Netherlands

Fax: +31-20-4440554

t.grasman@vumc.nl 